\title{
Analysis of the post-partum vaginal repair by injecting platelet-rich plasma; a study undertaken in Saudi German hospital K.S.A
}

\author{
Dr. Hassan El Motawkel Ala Allah HASSAN SOLIMAN ${ }^{\star 凶}$ \\ HOD \& Consultant Obstetrics \& GynecologY, Saudi German Hospital, Aseer, KSA. \\ Corresponding author's Email: obgyn1.asr@sghgroup.net
}

\section{ABSTRACT}

Aim. The research was based on the objective of vaginal recovery after vaginal delivery of women. PRP was used to determine whether the effects of the injecting PRP on vagina made any difference on vaginal prolapse repair or not. Therefore, the primary goal was to find the application of the PRP on the case of vaginal tear recovery of the mothers. Methods. The observational approach was utilized to conduct the following research. We examined $(p=210)$ participants, while study duration was 10 months from November 2017 to August 2018. Results. The outcomes were $100 \%$ positive in the researcher's cohort since all the participants responded well while recovered fast than the usual estimated time. Conclusion. Injecting PRP for repairing vaginal tear is considered to be optimizing for the general medical background patients whereas, for the long-term follow-up, the study requires to get the large numbers of participants in order to make the research generic.

\author{
Original Article \\ PII: S225199391900019-9 \\ Rec. 06 June 2019 \\ Rev. 24 August 2019 \\ Pub. 25 September 2019 \\ Keywords \\ Post-Partum, \\ Vaginal Tear, \\ Vaginal Repair, \\ Platelet-Rich Plasma, \\ Gynecological Study
}

\section{INTRODUCTION}

During the vaginal delivery, it is common to have perineal postpartum tear due to stretching of the vagina. It usually causes the tear of vaginal layers which eventually causes the temporary injury [1]. The degrees of vaginal tears are divided into 4 categories. While these degrees depend upon the severity of the tear, in the first degree tear, it includes the tear of vaginal mucosa and the connective tissue [2]. In the second degree tear, it involves the tear of vaginal mucosa and connective tissue along with the underlying muscles. For the third degree tear, it involves the complete transection of an anal sphincter [3-5]. And the last degree tear includes the tear of rectal mucosa [6]. A woman may suffer from any of these after delivery while just how there are several degrees of injury [7], there are different method for its recovery as well $[8,9]$.

The following research is based on the postpartum vaginal repair by injecting Platelet-rich plasma (PRP). The primary objective of the research study is to analyze and evaluate the use and benefits of PRP in order to know its significance and in the area of postpartum vaginal repair.

\section{MATERIAL AND METHODS}

The observational study method was implied in the following research. The study was undertaken at tertiary referral unit in K.S.A. Saudi German Hospital, Aseer. Whereas, the participants were undergo observations for the research purposes. The participants for the research comprised of 210 laboring women between 22-46 years old.

\section{Ethical approval}

The review board and ethics committee of Saudi German Hospital, Aseer approved the study protocol and informed consents were taken from all the participants.

\section{Limitations}

The study includes some of the significant limitations which are significant to come in the observation. Those are given as follow: The observational study lacks in providing the conclusive results or the authentic 
evidence as a result. Moreover, date limitations also play their role in making evidence weak. In order to overcome these limitations, it is essential to conduct a randomized controlled trial. The sample size of the participants limits the research to get appropriate conclusion and generalized outcome. For that reason, it is essential to carry the evidence-based research along with the large sample to make the outcomes generalized.

\section{Procedure and analysis}

The following study was undertaken in the time period of 10 months in which 210 laboring women between the ages of 22 to 46 were the participants. These participants were critically observed in order to analyze the application of PRP in vaginal repair.

The infiltration was made by using $20 \mathrm{ml}$ of Lidocaine (2\%) with 1 Amp Vasopressin 20 IU + $30 \mathrm{ml}$ Normal Saline +/- Sedation Inj. Dormicum 15mg/3ml. the major factors that have the significant role in the observational study include The Surgical Technique including Vaginoplasty and Perinorraphy which depends upon predelivery evaluation of vaginal laxity, widening, distance between the vagina and anus, any varicosities and mass. Following the experimental procedure, the participants were provided the sedation and after that the vasoconstrictor and local Analgesia Solution in both vaginal wall and perineum. The re-evaluation after the delivery was performed which further included: Careful dissection of the vaginal wall equally starting from the apex till the mucocutaneous junction at the introitus, two to three stitches at the deep and superficial perineal muscles and levator ani muscles and removal of the all excess vaginal tissues. After that the procedure proceeded by suturing the vaginal wall starting from the apex until the hymen ring and the one deep as well as a high stitch to approximate the bulbospongiosus muscle on both sides. The suturing was completed until the mucocutaneous junction while two or three stitches were tied muscles and interrupted stitches including subcuticular stitches of the perineal area. After completion of the repair process, inject $\pm 4.5-5 \mathrm{ml}$ of PRP which was already prepared at the time of delivery after extraction of 8-9 $\mathrm{ml}$ blood from the patient and put in the tube and centrifuge for 5 minutes to separate the PRP from the whole blood. Afterwards the PRP is injected to subcutaneous and subvaginal for further experimental approach. In the last compression and assurance of the heamostasis by vaginal back after catheterization, analgesia (mainly non-steroidal anti-inflammatory supplements) was done.

Furthermore, the statistical measurements of the parity and the age of participants are elaborated in tables 1 and 2. Any participant with any medical disorders e.g. hypertensive, diabetic, hypothyroid was well controlled before implication of the treatment. Thirteen of the women were diagnosed with hypertensive but not pre-eclampsia symptoms. Seventeen of them were Anemic with the Hb below 10.5. 41 of the women were diagnosed diabetic while the experiment was obtained on total 210 numbers of women from 22 to 46 years of age. Weight of the participants was measured between 63 to $114 \mathrm{~kg}$.

Table 1. Characteristics of the participants of the study

\begin{tabular}{lc}
\hline Characteristics & $22-46$ years \\
\hline Age & $69-117 \mathrm{~kg}$ \\
Weight & $14.76 \%$ \\
Medical disorder & $6.19 \%$ \\
$\quad$ Diabetic & $27.14 \%$ \\
Hypertensive & $0.95 \%$ \\
Hypothyroid & $5.23 \%$ \\
Epilepsy & $1.42 \%$ \\
Multiple medical disorder & $3.33 \%$ \\
Diabetic and hypertensive & \\
Diabetic and hypothyroid & $66.19 \%$ \\
Hypertensive and hypothyroid & $33.80 \%$ \\
Parity &
\end{tabular}


Table 2. Vaginal Prolapse of the Participant

\begin{tabular}{lc}
\hline Vaginal prolapse & Percentage \\
\hline Minor degree $\left(1^{\text {st }}\right.$ degree tear $)$ & $19.52 \%$ \\
Moderate degree $\left(2^{\text {nd }}\right.$ degree tear $)$ & $52.85 \%$ \\
Severe degree $\left(3^{\text {rd }}\right.$ degree tear $)$ & $22.61 \%$ \\
\hline
\end{tabular}

\section{RESULTS AND DISCUSSION}

After deeply analyzing the outcomes and observations made on the participant in ten months' time period, the researcher concluded the approach towards vaginal repair immediately after delivery is effective and more feasible. Furthermore, it adverts that the addition of vasopressin and lidocaine infiltration helps to prevent heavy blood loss and leads to prolong the analgesic effect. There were multiple more advantages observed during the observation like more analgesics time, cosmetic appearance, less infection and less dehiscence of the wound. Therefore the participant of the study $(\mathrm{p}=210)$ along with mediocre medical background responded well to the experimental vaginal repair experiment. Hence, the study was proved to be $100 \%$ successful whereas, for long-term follow-up, there is a need for large sample of participants for further evaluation and comparison.

The average size of a baby's head is 11.4 centimeters in diameter. The average diameter of a woman's vagina (according to a study) is 2.1 to 3.5 centimeters [10]. This initiates the scenario of complication in delivery [9-12]. Perhaps, some of the women do not require vaginal tear to deliver a child but some of them experience different degrees of the vaginal tear [13]. The process of repairing vagina takes long while the sensitivity of area makes it critical to handle [14]. That is why different approaches are usually followed in order to speed up the repair of an organ [15]. Usually the initial steps for the tear include suturing and stitches after that different medicines are used to cure the stitches further $[13,15]$. This particular research follows the idea of injecting PRP for speeding up the process of vaginal repair while the observational study was prioritized on the basis of its advantages defined as follow:

Through the PRP approach for vaginal repair, there is a significant decrease in blood loss as well as time of the repair $[15,16]$. It provides more analgesics time while providing more cosmetic appearance later on [15]. There are also very fewer chances of infection as dehiscence of the wound as per the results advert. For the concept of PR, the Plasma is the portion of liquid which contains whole blood. It has the large of water and proteins, platelets to circulate within the body for healing purpose [14]. Platelet activation plays a key role in the body's natural healing process [15]. Its major application is to heal the tissues of the body and has been used for multiple medical purposes in history.

\section{CONCLUSION}

The applications of Platelet-rich plasma (PRP) was proved to be significant for the vaginal repair after first, second and third-degree tear of women during vaginal delivery. The necessary measurements were made to check the medical condition of the study participants and the approach towards new treatment was applied to them in order to observe its outcomes. The researcher took the consent of the laboring women before the experiment and it was conducted with all security measures from healthcare perspective.

\section{DECLARATIONS}

Funding statement

This research did not receive any specific grant from funding agencies in the public, commercial, or notfor-profit sectors.

\section{Conflict of interests}

Authors do not have any conflict of interests.

\section{REFERENCES}

1. Woodman PJ and Graney DO. Anatomy and physiology of the female perineal body with relevance to obstetrical injury and repair. Clinical Anatomy: The Official Journal of the American Association of Clinical Anatomists and the British Association of Clinical Anatomists, 2002, 15(5), 321-334. (Google Scholar ; https://doi.org/10.1002/ca.10034) 
2. Weber $\mathrm{AM}$ and Walters MD. Anterior vaginal prolapse: review of anatomy and techniques of surgical repair. Obstetrics \& Gynecology, 1997, 89(2), 311-318. (Google Scholar ; https://doi.org/10.1016/S0029-7844(96)00322-5)

3. Majhail NS, Rizzo JD, Lee SJ, Aljurf M, Atsuta Y, Bonfim C, Burns LJ, Chaudhri N, Davies S, Okamoto S and Seber A. Recommended screening and preventive practices for long-term survivors after hematopoietic cell transplantation. Hematology/oncology and Stem Cell Therapy, 2012, 5(1), pp.1-30. (Google Scholar ; https://doi.org/10.5144/1658-3876.2012.1)

4. Petros PP. Development of generic models for ambulatory vaginal surgery-a preliminary report. International Urogynecology Journal, 1998, 9(1), 19-27. (Google Scholar; https://doi.org/10.1007/BFo1900537)

5. Petros PEP and Ulmsten UI. An integral theory of female urinary incontinence: experimental and clinical considerations. Acta Obstetricia et Gynecologica Scandinavica, 1990, 69(S153), 7-31. (Google Scholar ; https://doi.org/10.1111/j.1600-0412.1990.tbo8027.x )

6. Haylen BT, De Ridder D, Freeman RM, Swift SE, Berghmans B, Lee J, Monga A, Petri E, Rizk DE, Sand PK and Schaer GN, An International Urogynecological Association (IUGA)/International Continence Society (ICS) joint report on the terminology for female pelvic floor dysfunction. Neurourology and Urodynamics: Official Journal of the International Continence Society, 2010, $29(1), 4-20$. (Google Scholar ; https://doi.org/10.1002/nau.20798)

7. Pathi SD, Acevedo JF, Keller PW, Kishore AH, Miller RT, Wai CY and Word RA. Recovery of the injured external anal sphincter after injection of local or intravenous mesenchymal stem cells. Obstetrics \& Gynecology, 2012, 119(1), 134-144. (Google Scholar ; https://doi.org/10.1097/AOG.obo13e3182397009)

8. Gyhagen $\mathrm{Ml}$, Bullarbo $\mathrm{M}$, Nielsen TF and Milsom I. Prevalence and risk factors for pelvic organ prolapse 20 years after childbirth: a national cohort study in singleton primiparae after vaginal or caesarean delivery. BJOG: An International Journal of Obstetrics \& Gynaecology, 2013, 120(2), 152-160. (Google Scholar ; https://doi.org/10.1111/1471-0528.12020 )

9. Dietz HP, Pelvic floor trauma in childbirth. Australian and New Zealand Journal of Obstetrics and Gynaecology, 2013, 53(3), pp.220-230. (Google Scholar ; https://doi.org/10.1111/ajo.12059)

10. Dietz HP, Shek KL, Chantarasorn V and Langer SE, Do women notice the effect of childbirth-related pelvic floor trauma? Australian and New Zealand Journal of Obstetrics and Gynaecology, 2012, 52(3), 277-281. (https://doi.org/10.1111/j.1479-828X.2012.01432.x ; Google Scholar)

11. Pergialiotis V, Vlachos D, Protopapas A, Pappa K and Vlachos G. Risk factors for severe perineal lacerations during childbirth. International Journal of Gynecology \& Obstetrics, 2014, 125(1), 6-14. (https://doi.org/10.1016/j.ijgo.2013.09.034 ; Google Scholar)

12. De Vos RJ, Weir A, van Schie HT, Bierma-Zeinstra SM, Verhaar JA, Weinans H and Tol JL. Platelet-rich plasma injection for chronic Achilles tendinopathy: a randomized controlled trial. Jama, 2010, 303(2), 144-149. (https://doi.org/10.1001/jama.2009.1986 ; Google Scholar)

13. Hauck YL, Lewis L, Nathan EA, White C and Doherty DA, Risk factors for severe perineal trauma during vaginal childbirth: a Western Australian retrospective cohort study. Women and Birth, 2015, 28(1), 16-20. (; https://doi.org/10.1016/j.wombi.2014.10.007 ; Google Scholar)

14. Kon E, Buda R, Filardo G, Di Martino A, Timoncini A, Cenacchi A, Fornasari PM, Giannini S and Marcacci M. Platelet-rich plasma: intraarticular knee injections produced favorable results on degenerative cartilage lesions. Knee Surgery, Sports Traumatology, Arthroscopy, 2010, 18(4), 472-479. (https://doi.org/10.1007/s00167-009-0940-8 ; Google Scholar)

15. Lacci, K.M. and Dardik, A., Platelet-rich plasma: support for its use in wound healing. The Yale Journal of Biology and Medicine, 2010 , 83(1), p.1. (Google Scholar)

16. Castricini R, Longo UG, De Benedetto M, Panfoli N, Pirani P, Zini R, Maffulli N and Denaro V. Platelet-rich plasma augmentation for arthroscopic rotator cuff repair: a randomized controlled trial. The American Journal of Sports Medicine, 2011, 39(2), 258-265. (Google Scholar ; https://doi.org/10.1177/0363546510390780) 